\title{
Development of calcium phosphate based apatite from hen's eggshell
}

\author{
K PRABAKARAN, A BALAMURUGAN and S RAJESWARI* \\ Department of Analytical Chemistry, University of Madras, Guindy Campus, Chennai 600 025, India
}

MS received 15 July 2004; revised 10 January 2005

\begin{abstract}
Stoichiometric hydroxyapatite with Ca/P molar ratio, 1.67, was synthesized using hen's eggshell as calcium source and phosphoric acid by precipitation method. Conventional EDTA titration and gravimetric methods were adopted to estimate the amount of calcium and phosphorous, respectively. Fourier-transform infrared (FT-IR) and X-ray diffraction (XRD) techniques were employed to investigate the formation of the HAP phase. Thermal analysis (TG-DTA) was carried out to investigate the thermal stability of HAP powder. FT-IR spectra show the characteristic peaks for phosphate and hydroxyl groups. XRD results reveal that the major characteristic peaks of HAP appear in the region of approximately $26^{\circ}, 28^{\circ}, 2^{\circ}, 30-35^{\circ}, 39^{\circ}, 46^{\circ}, 4^{\circ}$ and $50^{\circ}(2 \theta)$ and also indicate that there are no occurrences of secondary phases during HAP formation. TGDTA result depicts that the synthesized HAP was stable up to $1300^{\circ} \mathrm{C}$.
\end{abstract}

Keywords. Hydroxyapatite (HAP); eggshell; phosphoric acid; precipitation.

\section{Introduction}

It is well known that the composition of human bone is an inorganic/organic hybrid consisting of $\sim 70 \%$ apatitic calcium phosphate and $30 \%$ organic (largely collagen) constituents, by weight (Cowin et al 1987). The apatitic calcium phosphate of bone mineral consists of carbonate, small amount of sodium, magnesium and other trace elements. The submicroscopic crystal of calcium phosphate in bone resembles the crystal structure of synthetic hydroxyapatite, [HAP, $\mathrm{Ca}_{10}\left(\mathrm{PO}_{4}\right)_{6}(\mathrm{OH})_{2}$ ] (Sinha et al 2001). Hence HAP has received great attention in the field of biomedical engineering.

Artificially prepared HAP, with the same structure as that of apatitic phosphate of natural bone has good biocompatibility with the human organism. It forms chemical bond with the host hard tissue and for this reason, it is widely used in medical applications as implants, as coating on prostheses or as bone filling material. HAP powder can be synthesized via numerous production routes, using a range of different reactants. Some of the processing techniques include dry process (Fowler 1974), wet chemical method (precipitation), hydrolyzation of calcium phosphate (Monma and Kamiyua 1987), hydrothermal synthesis (Takeo et al 1989; Sada et al 1991), spray pyrolysis (Senya and Akira 1987), freeze-drying (Takeo et al 1987), gel-diffusion, sol-gel technique (Yoshio et al 1990) and electrochemical deposition. Of these methods, precipitation scores over other processes by virtue of being simple, cheap and easy application in industrial produc-

*Author for correspondence (nivapraba@ rediffmail.com) tion. Moreover, HAP prepared by precipitation also has the feature of small size, low crystallinity and high surfacial activation, which can meet different demands (Liu et al 2001).

Several methods of chemical synthesis have been developed to prepare HAP powder using various types of $\mathrm{Ca}$ and P sources (Asada et al 1987; Osaka et al 1991; Koumoulidis et al 2001; Milev et al 2003). In the present investigation, an attempt is made to synthesize pure and biocompatible HAP powder by using hen's eggshell as the Ca source. The eggshell consists of about 94-97\% of $\mathrm{CaCO}_{3}$ and the other $3 \%$ is organic matter and egg pigment. There are also as many as 8000 microscopic pores in the shell itself. The eggshell was found to be a waste material after egg's usage. Hence in this study, the eggshell, a waste material, has been used as a calcium precursor to synthesize pure $\mathrm{HAP}$ with $\mathrm{Ca} / \mathrm{P}$ ratio, 1.67 , through wet chemical method. The synthesized powder was characterized by FT-IR, TG-DTA and XRD techniques.

\section{Experimental}

\subsection{Synthesis of HAP}

Uncrushed and washed eggshell was calcined in an air atmosphere at $900^{\circ} \mathrm{C}$ for $1 \mathrm{~h}$. The amount of calcium present in the calcined eggshell was estimated. A stoichiometric amount of calcined eggshell was dispersed in well-degassed distilled water. Under rigorous stirring reagent grade orthophosphoric acid solution (0.6 M) was added in drops at a controlled rate to the suspension at room temperature. Initially, the $\mathrm{pH}$ of the solution was 
found to be 12, but at the end of addition of phosphoric acid, it decreased to $8 \cdot 5$. After completion of the addition, the precipitate formed was subjected to ripening (aging) treatment for $24 \mathrm{~h}$ followed by $1 \mathrm{~h}$ refluxing. It was then stirred for another $25 \mathrm{~min}$ without heating and left for over $10 \mathrm{~h}$. The precipitate was filtered and thoroughly washed with double distilled water and filtered again. After drying at $80^{\circ} \mathrm{C}$ for $3 \mathrm{~h}$, the precipitate was calcined at various temperatures, say, $400^{\circ} \mathrm{C}, 700^{\circ} \mathrm{C}$ and $900^{\circ} \mathrm{C}$ for $2 \mathrm{~h}$.

\subsection{Characterization of powder}

2.2a Chemical analysis: The chemical analysis was performed to confirm the $\mathrm{Ca} / \mathrm{P}$ molar ratio (1.67) of the synthesized powder. The Ca was analysed by EDTA titration and $\mathrm{P}$ by conventional gravimetric method. The concentration of $\mathrm{Na}$ and $\mathrm{Mg}$ present in the sample were analysed using atomic absorption spectrophotometer (AAS) by GBC Avanta system, Germany.

2.2b FT-IR spectral analysis: The formation of the HAP phase was tested by FT-IR spectral analysis. FT-IR transmittance spectra of the crushed samples were obtained in the $4000-400 \mathrm{~cm}^{-1}$ region on infrared spectrometer (SHIMADZU model 8300 ) by using $\mathrm{KBr}$ pellet technique $(0 \cdot 1 \mathrm{wt} \%)$.

2.2c $X$-ray diffraction analysis: The crystallographic phases of the synthesized HAP powders were identified by using X-ray diffractograms (XRD). X-ray analysis was performed by RICH SEIFERT model 3000 diffraction system, Germany, using $\operatorname{CuK} \alpha(\lambda=1.5405 \AA)$ radiation. The intensity data were collected in $0.02^{\circ}$ steps in the $2 \theta$ range, $10-70^{\circ}$. The full width at half maximum (FWHM) of the 002 and 003 reflections were taken as a measure of crystallinity.

2.2d TG-DTA analysis: The weight loss and thermal stability of the samples were also evaluated from the thermogravimetric analysis data. An HETZSCH-Geratebau $\mathrm{GmBH}$ thermal analyser having simultaneous thermal analyser (STA) $409 \mathrm{C}$ microbalance with a heating rate

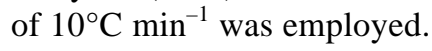

\section{Results and discussion}

\subsection{Chemical analysis}

The phase constitution and chemical homogeneity of the sample were examined by quantitative chemical analysis via EDTA titration, gravimetry and AAS. The Ca/P molar ratio was found to be 1.67 , which indicates the formation of pure hydroxyapatite. The percentage compositions of $\mathrm{Ca}, \mathrm{P}, \mathrm{Na}$ and $\mathrm{Mg}$ are presented in table 1 .

\subsection{FT-IR spectral studies}

Figure 1 shows FT-IR spectra of hydroxyapatite heated at various temperatures, say, $80^{\circ} \mathrm{C}, 400^{\circ} \mathrm{C}, 700^{\circ} \mathrm{C}$ and $900^{\circ} \mathrm{C}$. The infrared band positions and their assignments are summarized in table 2 . The spectral data indicate that carbonate ion is present in the prepared HAP samples. The carbonate ion substitution is identified by characteristic doublet peak of the carbonate ions around 1420 and
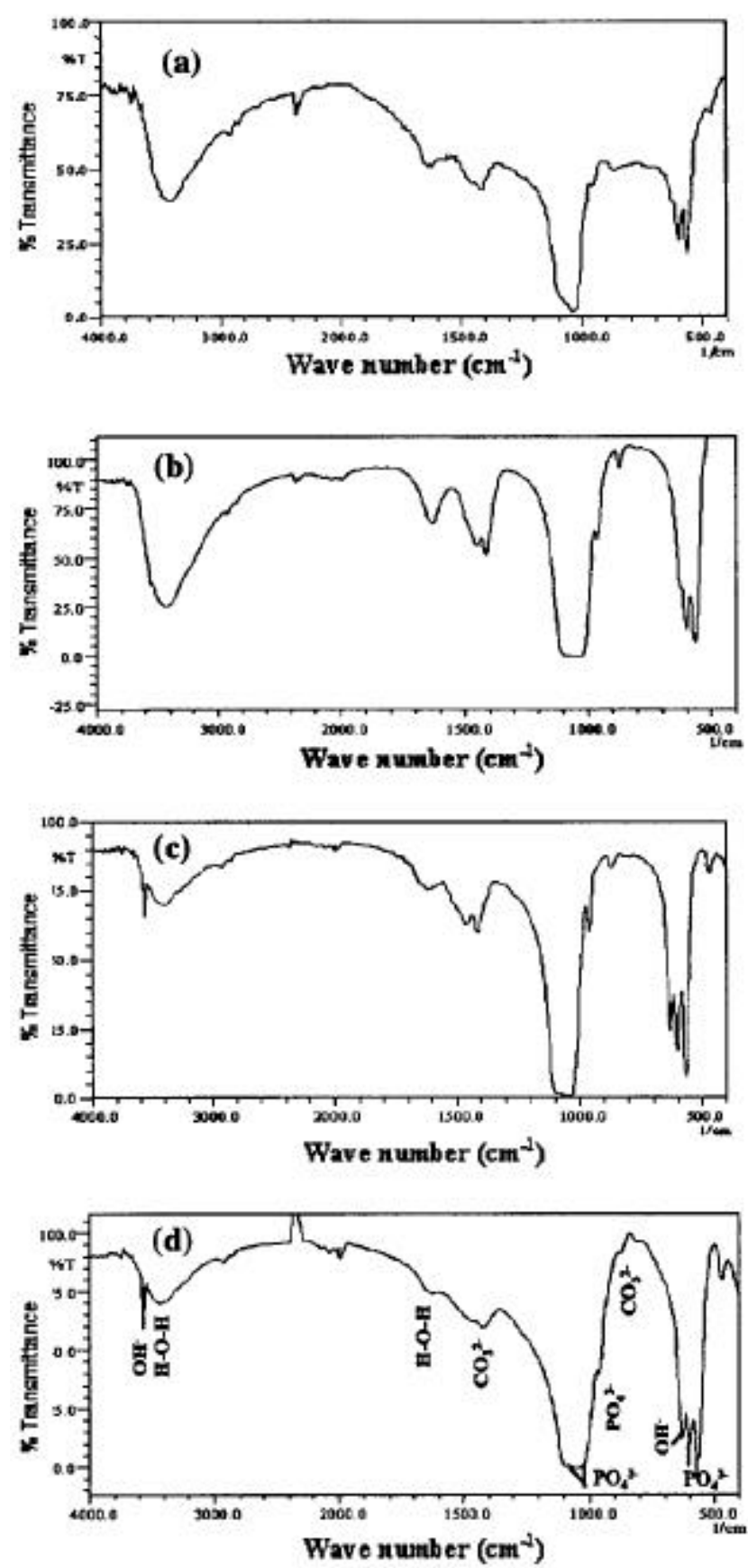

Figure 1. FT-IR spectra of HAP heated at (a) $80^{\circ} \mathrm{C}$, (b) $400^{\circ} \mathrm{C}$, (c) $700^{\circ} \mathrm{C}$ and (d) $900^{\circ} \mathrm{C}$. 
$1480 \mathrm{~cm}^{-1}$ and a singlet peak at $875 \mathrm{~cm}^{-1}$ (Stoch et al 2000), which is attributed to the vibrational modes of the carbonate ions, substituted at the phosphate site. For samples heated at $80^{\circ} \mathrm{C}$ these peaks were rather broad, and it became well defined for those samples heated at $400^{\circ} \mathrm{C}$ and $700^{\circ} \mathrm{C}$. However, peaks at $875 \mathrm{~cm}^{-1}$ and $1480 \mathrm{~cm}^{-1}$ became ill-defined when the samples were heated to $900^{\circ} \mathrm{C}$. This confirms the elimination of $\mathrm{CO}_{3}^{2-}$ ion at higher temperature. The broad bands observed at around 1650 and $3440 \mathrm{~cm}^{-1}$ indicate adsorbed $\mathrm{H}_{2} \mathrm{O}$ in the samples. The bands at around $3440 \mathrm{~cm}^{-1}$, which is due to adsorbed water overlaps with the weak bands at around $3570 \mathrm{~cm}^{-1}$, which is due to structural $\mathrm{OH}$ and these bands are not clearly visible for the samples heated at $80^{\circ} \mathrm{C}$. The band (bending) due to structural $\mathrm{OH}$ in HAP also occurs at around $633 \mathrm{~cm}^{-1}$. This peak for materials heated at $80^{\circ} \mathrm{C}, 400^{\circ} \mathrm{C}, 700^{\circ} \mathrm{C}$ appear as weak shoulders that gradually deepen and they merge to become a well-developed peak after heating at $900^{\circ} \mathrm{C}$. This evolution also indicates good crystallinity for the material heated at higher temperature. The characteristic frequencies derived from $\mathrm{PO}_{4}^{3-}$ modes are seen at around $1090 \mathrm{~cm}^{-1}$, $1040 \mathrm{~cm}^{-1}, 964 \mathrm{~cm}^{-1}, 605 \mathrm{~cm}^{-1}$ and $570 \mathrm{~cm}^{-1}$ and are better resolved with increase in heating temperature.

Table 1. The percentage composition of the constituents of synthesized HAP.

\begin{tabular}{lc}
\hline Constituents of HAP & Composition (wt\%) \\
\hline Calcium & $39 \cdot 298$ \\
Phosphorous & $18 \cdot 240$ \\
Sodium & $0 \cdot 117$ \\
Magnesium & $0 \cdot 209$ \\
\hline
\end{tabular}

\section{$3.3 X$-ray diffraction studies}

A typical XRD profile of HAP powder synthesized by wet chemical method has been shown in figure 2. The XRD phase analysis has been performed using JCPDS card number $09-0432$. The samples heated at $80^{\circ} \mathrm{C}$ show broad peaks indicating the formation of microcrystalline phases, which increase with heating temperature. The crystallite sizes were calculated using Scherrer's relationship,

$$
d=k \lambda / \beta \cos \theta
$$

where $d$ is the average diameter in $\AA, k$ the shape factor and $\beta$ the broadening of the diffraction angle. The Bragg reflections at (002) and (003) planes of HAP were considered to calculate the crystallite size. The size of the crystallites for these planes were $34 \mathrm{~nm}$ and $10 \mathrm{~nm}$ for the samples heated at $80^{\circ} \mathrm{C}, 68 \mathrm{~nm}$ and $69 \mathrm{~nm}$ for those samples heated at $900^{\circ} \mathrm{C}$. The expansion does indicate a structural change in the lattice. It should be noted that materials prepared via low temperature wet chemical processes are known to accommodate various ionic species, e.g. $\mathrm{H}_{3} \mathrm{O}^{+}, \mathrm{HPO}_{4}^{2-}$ etc and they may decompose in a variety of ways leading to structural changes (Simpson 1968).

\section{$3.4 \quad T G-D T A$ results}

Figure 3 illustrates the results of thermal analysis of HAP precursor. Two exothermic peaks at $147.5^{\circ} \mathrm{C}$ and $489^{\circ} \mathrm{C}$ and two endothermic peaks at $1335^{\circ} \mathrm{C}$ and $1363^{\circ} \mathrm{C}$ were observed in the DTA. In the investigated temperature range, there are three regions of interest in the TG curve: (i) up to $300^{\circ} \mathrm{C}$, corresponding to the removal of adsorbed water, (ii) between 300 and $700^{\circ} \mathrm{C}$, corresponding to $\mathrm{HPO}_{4}^{2-}$ decomposition according to the reaction: $2 \mathrm{HPO}_{4}^{2-}$

Table 2. Assignments of the observed vibrational frequencies of HAP heated at various temperatures.

\begin{tabular}{lcccc}
\hline & \multicolumn{4}{c}{ Observed vibrational frequencies $\left(\mathrm{cm}^{-1}\right)$} \\
\cline { 2 - 5 } Assignments & $\begin{array}{c}\text { Heating temp. } \\
\left(80^{\circ} \mathrm{C}\right)\end{array}$ & $\begin{array}{c}\text { Heating temp. } \\
\left(400^{\circ} \mathrm{C}\right)\end{array}$ & $\begin{array}{c}\text { Heating temp. } \\
\left(700^{\circ} \mathrm{C}\right)\end{array}$ & $\begin{array}{c}\text { Heating temp. } \\
\left(900^{\circ} \mathrm{C}\right)\end{array}$ \\
\hline $\mathrm{PO}_{4}$ bend $v_{4}$ & 571 & 567 & 571 & 571 \\
$\mathrm{PO}_{4}$ bend $v_{4}$ & 607 & 605 & 603 & 604 \\
$\mathrm{Structural} \mathrm{OH}_{\mathrm{CO}_{3}^{-} \text {group }}^{635}$ & 632 & 632 & 633 \\
$\mathrm{PO}_{4}$ stretch $v_{1}$ & 875 & 876 & 875 & 875 \\
$\mathrm{PO}_{4}$ bend $v_{3}$ & 961 & 964 & 961 & 964 \\
$\mathrm{PO}_{4}$ bend $v_{3}$ & 1050 & 1039 & 1037 & 1035 \\
$\mathrm{CO}_{3}^{-}$group $\left(v_{3}\right)$ & 1090 & 1097 & 1096 & 1099 \\
$\mathrm{CO}_{3}^{-}$group $\left(v_{3}\right)$ & 1423 & 1416 & 1416 & 1423 \\
$\mathrm{H}_{2} \mathrm{O}$ adsorbed $\left(v_{2}\right)$ & 1479 & 1464 & 1466 & 1470 \\
$\mathrm{H}_{2} \mathrm{O}$ adsorbed & 1628 & 1636 & 1624 & 1630 \\
$\mathrm{Structural} \mathrm{OH}$ & 3418 & 3448 & 3426 & 3441 \\
$\mathrm{OH}$ stretch & - & 3570 & 3572 & 3572 \\
\hline
\end{tabular}



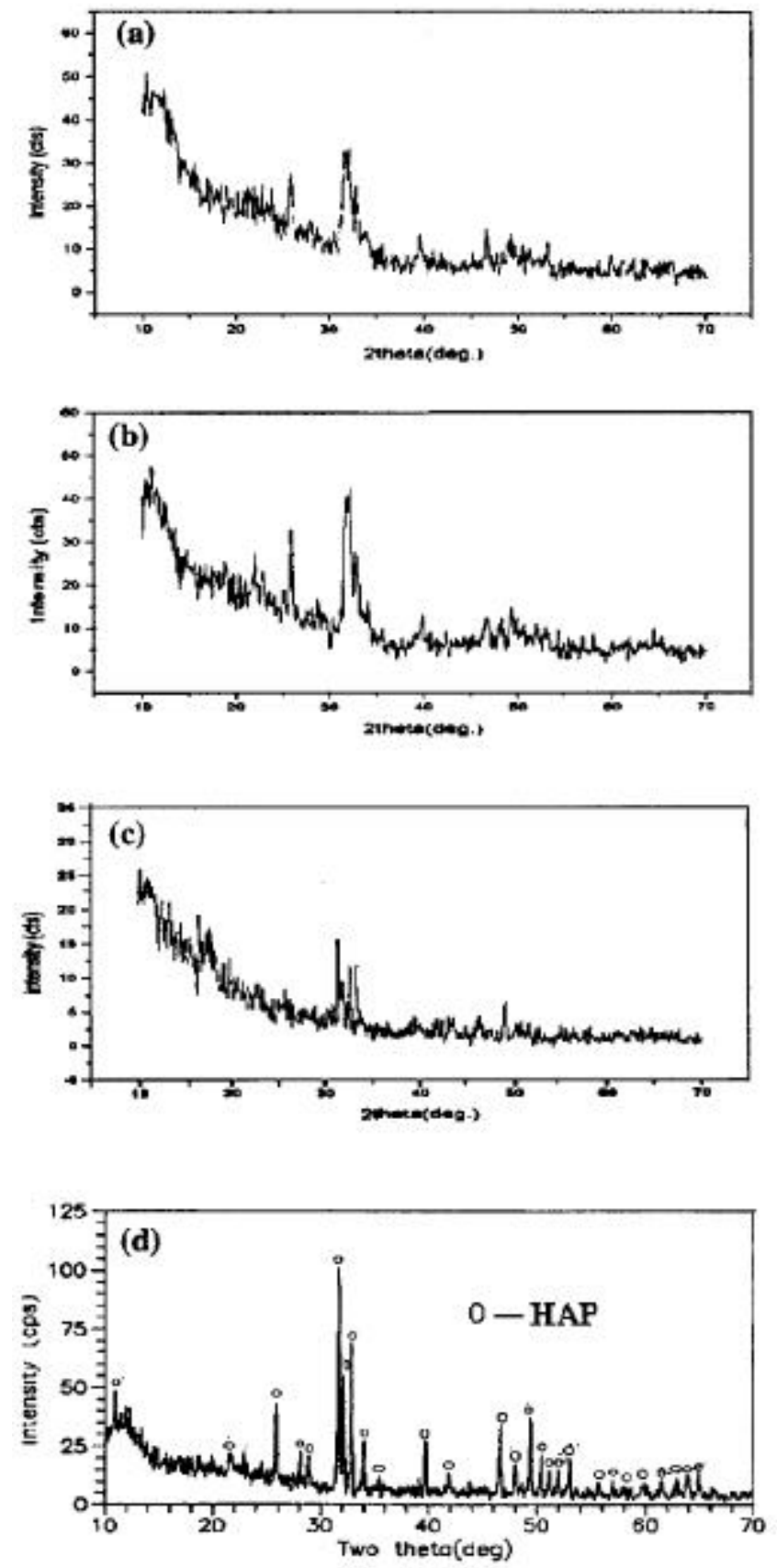

Figure 2. XRD pattern of HAP heated at (a) $80^{\circ} \mathrm{C}$, (b) $400^{\circ} \mathrm{C}$, (c) $700^{\circ} \mathrm{C}$ and (d) $900^{\circ} \mathrm{C}$.

$\rightarrow \mathrm{P}_{2} \mathrm{O}_{7}^{4-}+\mathrm{H}_{2} \mathrm{O}$. Removal of interstitial water may also take place in this temperature range and (iii) in the range $700-800^{\circ} \mathrm{C}$, reaction $\mathrm{P}_{2} \mathrm{O}_{7}^{4-}+2 \mathrm{OH}^{-} \rightarrow 2 \mathrm{PO}_{4}^{3-}+\mathrm{H}_{2} \mathrm{O}$ may take place.

The total weight loss measured upon heating to $300^{\circ} \mathrm{C}$ was $5.87 \%$, which is due to the elimination of adsorbed water. A weight loss in the range of $700-850^{\circ} \mathrm{C}$ was small compared with the loss measured at lower temperature and can be ascribed to the removal of interstitial water rather than to thermal decomposition of the samples. The

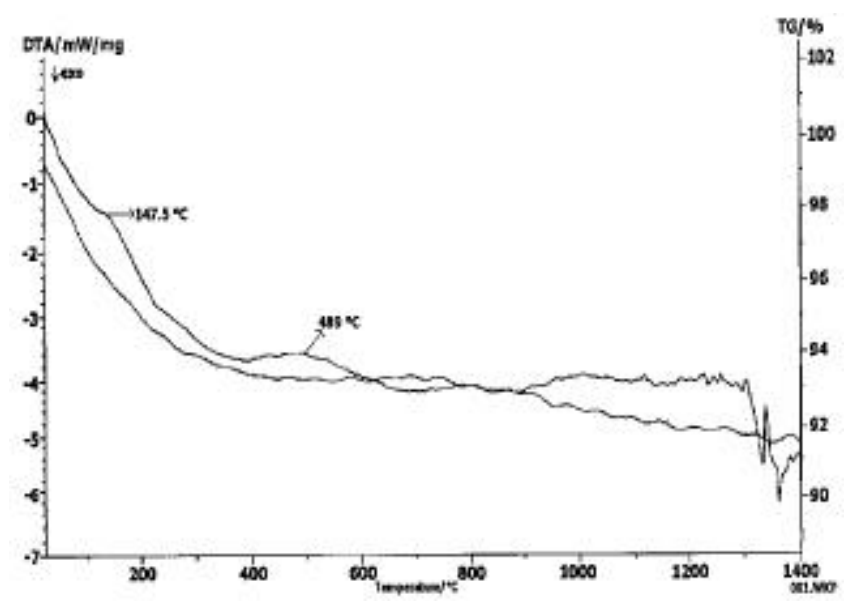

Figure 3. Thermal analysis of HAP.

endothermic peaks at $1335^{\circ} \mathrm{C}$ and $1363^{\circ} \mathrm{C}$ on the DTA curve was accompanied by a $8.56 \%$ weight loss on the TG curve, which was attributed to the decomposition of HAP to $\beta$-TCP or dihydroxylation.

\section{Conclusions}

Stoichiometric, pure and thermally stable HAP powder was synthesized using eggshell and phosphoric acid by precipitation method. FT-IR and XRD analyses indicated the phase purity and crystallinity of the HAP powder. TG-DTA results showed the thermal stability of HAP. The present study suggests the eggshell as a possible material-recycling technology for future waste management and ecology. Also, eggshell-originated HAP is a potential ceramic, which could be useful as an inexpensive ceramic for biomedical applications.

\section{Acknowledgement}

The authors are thankful to the UGC programme on "University with Potential for Excellence (UWPFE)" for rendering financial support to carry out the work.

\section{References}

Asada M, Oukami K, Nakamura S and Takahashi K $1987 \mathrm{~J}$. Ceram. Soc. Jap. 95703

Cowin S C, Vanburskirk W C and Ashaman R B 1987 Handbook of bioengineering (eds) R Skalak and S Chien (New York: McGraw-Hill)

Fowler B O 1974 Inorg. Chem. 13207

Koumoulidis G C, Vaimakia T C, Sdoukos A T, Boukos N K and Trapalis C C 2001 J. Am. Ceram. Soc. 841203

Liu Changsheng, Huang Yue, Shen Wei and Cui Jinghua 2001 Biomaterials 22301

Milev A, Kannangara G S K and Ben-Nissan B 2003 Mater. Lett. 572003

Monma H and Kamiyua V 1987 J. Mater. Sci. 224247 
Osaka A, Miura Y, Takeuchi K, Asada M and Takahashi K 1991 J. Mater. Sci. Mater. Med. 251

Sada V, Kumazawa V and Murakami Y 1991 Chem. Eng. Comm. 10357

Senya I and Akira O 1987 J. Ceram. Soc. Jap. 95759

Simpson D R 1968 Am. Miner. 531953

Sinha Amit, Ingle A, Munim K R, Vaidya S N, Sharma B P and Bhisey A N 2001 Bull. Mater. Sci. 24653
Stoch A, Jastrzebski W, Brozek A, Stoch J, Szaraniec J, Trybalska B and Kmita G 2000 J. Mol. Struct. 555375

Takeo H, Yasuhiko I and Hiroshi I 1987 J. Ceram. Soc. Jap. 95 825

Takeo H, Yasuhiko H and Murakami Y 1989 J. Mater. Sci. Lett. 8305

Yoshio M, Kazuo M and Sumio S 1990 J. Ceram. Soc. Jap. 98 1255 